\title{
A study on variants of focal segmental glomerulosclerosis and their relationship with various biochemical and demographic parameters in kidney biopsies; a single center study
}

\author{
Fahimeh Fatehi ${ }^{1}$, Seyed Mohsen Hosaini ${ }^{\circledR}{ }^{\circledR}$, Hamid Nasri ${ }^{1 *}$ \\ ${ }^{1}$ Department of Internal Medicine, Faculty of Medicine, Isfahan University of Medical Sciences, Isfahan, Iran \\ ${ }^{2}$ Department of Epidemiology and Statistics, Faculty of Health, Isfahan University of Medical Sciences, Isfahan, Iran
}

\section{A R T I C L E I N F O}

Article Type:

Original

\section{Article History:}

Received: 11 March 2019

Accepted: 3 May 2019

Published online: 27 May 2019

\section{Keywords:}

Focal segmental

glomerulosclerosis,

End-stage renal disease,

Columbia classification

\begin{abstract}
A B S T R A C T
Introduction: Focal segmental glomerulosclerosis (FSGS) is one of the most common glomerular diseases leading to end-stage renal failure. According to Columbia classification, there are five histologic variants for FSGS.

Objectives: There is no study about prevalence and clinic-pathological features of its variants up to now in Iran.

Patients and Methods: The study was conducted on renal biopsy reports in a laboratory center between 2011- 2015. Of 1108 patients, 234 had FSGS (either secondary or primary). Using light and immunofluorescence microscopies, the diagnosis and the variants of FSGS were determined (according to Columbia classification). Pathological findings like interstitial fibrosis and glomerular sclerosis, para-clinical findings including serum creatinine and proteinuria, and demographic features including gender and age were also recorded.

Results: Among 212 patients with primary form of FSGS, 58\% were males with the male-to-female ratio of 1.38: The mean age was $38.5 \pm 18.72$ years. Classic variant (not otherwise specified; NOS) was the most prevalent variant, comprising $89.1 \%$ of all cases. Tip variant comprised of $32.5 \%$, perihilar in $23.1 \%$, collapsing in $0.9 \%$, while cellular was detected in $0.5 \%$ of cases. Mean serum creatinine was $1.41 \pm 0.84 \mathrm{mg} / \mathrm{dL}$. Moreover, mean of proteinuria was $2201.8 \pm 1134.49 \mathrm{mg} / \mathrm{day}$. Mean interstitial fibrosis/tubular atrophy in the variants were; NOS in $14.9 \pm 10.87 \%$ of cases, Tip; $7.26 \pm 11.55 \%$ of cases and in perihilar was $10.79 \pm 15.75 \%$.

Conclusion: Our study indicates that NOS variant of FSGS is a highly prevalent variant in our patients. Among them, the highest proportion of interstitial fibrosis was seen in this variant.
\end{abstract}

Implication for health policy/practice/research/medical education:

The prevalence of variants of focal segmental glomerulosclerosis is different in various regions. The most common variant of focal segmental glomerulosclerosis in our region like most studies is NOS (classic) variant.

Please cite this paper as: Fatehi F, Hosaini SM, Nasri H. A study on variants of focal segmental glomerulosclerosis and their relationship with various biochemical and demographic parameters in kidney biopsies; a single center study. J Nephropharmacol. 2019;8(2):e24. DOI: 10.15171/npj.2019.24.

\section{Introduction}

Focal segmental glomerulosclerosis (FSGS) constitutes about $20-25 \%$ of patients who undergo renal biopsy for the diagnosis of glomerulonephritis. It is one of the most common glomerular diseases which leads to end-stage renal disease (1). FSGS has been known as a major cause of primary glomerular disease in adults in recent years, which occurs with nephrotic syndrome (2). FSGS alone is not a disease, but it is a clinicopathologic finding which is clinically determined in most cases of nephrotic syndrome. Its histologic form is determined in the presence of segmental sclerotic lesions in some glomeruli (not all of them) (3-5). This disease may be primary (idiopathic) or secondary to various causes (6). The prevalence of FSGS around the world is growing (7-12). In a study in Pakistan, its prevalence among adults with nephrotic syndrome has been reported to be $39.7 \%$ (13). In other studies in Pakistan, its prevalence among children has been reported to be $38.14 \%$ which is the most common pathology among children with nephrotic syndrome after minimal change disease in the country $(14,15)$. In another study in Korea, $5.6 \%$ of primary glomerular disease has been reported to 
be FSGS (16).

According to morphologic findings of light microscopy, a group of pathologists proposed a standard classification system named Columbia classification (2003). Based on this classification, five histologic variants have been defined for FSGS as follows $(17,18)$.

- Not otherwise specified (NOS) (Classic variant)

- Cellular variant

- Tip variant

- Collapsing variant

- Perihilar variant

\section{Objectives}

This study was carried out to determine the frequency of each variant of FSGS and also to assess the relationship between various demographic and clinical factors with the morphologic characteristics of FSGS in a single laboratory experience.

\section{Patients and Methods \\ Patient selection}

This research is a cross-sectional study. This study was conducted on renal biopsies which referred to a single laboratory center between 2011 and 2015. All biopsies were examined by a single nephropathologist using light microscopy and immunofluorescence.

Kidney biopsy specimens for both light microscopy and immunofluorescence were received in both formaldehyde and physiologic serum and ice respectively. For each patient two samples were obtained, one for light microscopy and another one for immunofluorescence microscopy (IF). Sample related to immunofluorescence was immediately placed in tissue tech material and then was cut by Cryostat device and then was prepared with IgA, IgG, IgM, C3, C1q and fibrin antibodies. Detection of focal and segmental glomerulosclerosis was conducted by the absence of IgA, IgG and C1q deposits in the tuft of the glomeruli. It is worth mentioning that few deposits of C3 or IgM may be detected in focal and segmental glomerulosclerosis.

To evaluate the morphologic lesions by light microscopy, samples in formalin were initially processed then blocked using paraffin and were stained with H\&E, Jones, Periodic acid-Schiff (PAS) and Masson's trichrome staining. Exclusion criterion was biopsies below 8 glomeruli.

When working with light microscopy, first, normal glomeruli as well as totally sclerotic glomeruli are recorded. Then description of glomerular damages and variants focal and segmental glomerulosclerosis were determined. Accordingly proportion of interstitial damage by fibrosis and tubular atrophy were determined. Variants of FSGS were conducted according to our previous publication (19).

\section{Ethical considerations}

The research followed the tenets of the Declaration of
Helsinki. In this research, we followed all the ethical considerations related to research on patients' clinical samples. The study was approved by the Research Committee and the Ethical Committee of Isfahan University of Medical Sciences (\#394547). This study was extracted from M.D thesis of Fahemeh Fatehi in Isfahan University of Medical Sciences.

\section{Statistical analysis}

Data were analyzed based on IBM SPSS Statistics 22. For continuous variables such as age, creatinine, urine protein in 24 hours, or percentage of interstitial fibrosis, mean and standard deviation were used. Frequency of each variant was determined on the basis of gender. Statistical analysis was performed using appropriate statistical tests such as chi-square test, ANOVA tests, Mann-Whitney U test or Kruskal-Wallis test. In this study $P$ value less than 0.05 was considered as significant.

Results

Around 1108 renal biopsies studied. Overall, 234 patients with focal and segmental glomerulosclerosis have been reported which all had inclusion criteria. About 212 patients (90.6\%) had primary or idiopathic form of FSGS while 22 patients $(9.4 \%$ ) had a secondary form (according to patients 'data provided in the pathology reports). In this study, secondary forms of FSGS were excluded.

Of 212 patients (primary form) 123 (58\%) were male since $89(42 \%)$ were female, with male to female ratio of 1.38 to 1 . Ages were from 1 to 93 years and the mean of age was $38.5 \pm 18.72$ years.

The mean serum creatinine was $1.41 \pm 0.84 \mathrm{mg} / \mathrm{dL}$, with creatinine range of 0.5 to $7 \mathrm{mg} / \mathrm{dL}$. The 24 -hour proteinuria ranged from $221 \mathrm{mg} / \mathrm{d}$ to $6600 \mathrm{mg} / \mathrm{d}$ while the mean of 24-hour proteinuria was $2201.8 \pm 1134.49 \mathrm{mg} / \mathrm{d}$.

Results of this study showed that not otherwise specified (NOS) variant of FSGS was the most common variant which included 91 (42.9\%) of patients. Tip variant included 69 people (32.5\%), perihilar variant in 49 patients $(23.1 \%)$, collapsing variant in two patients $(0.9 \%)$ while cellular variant was detected in one patient $(0.5 \%)$.

Due to the low number of collapsing (2 patients) and cellular (1 patient) variants, these two variants were removed to detect correlations correctly. Data about the variants are shown in Table 1.

The average age of the NOS variant of FSGS was $41.06 \pm 20.49$ years, in tip was $32.13 \pm 16.28$ years while in perihilar variant it was $42.77 \pm 16.84$ years. There was a significant correlation between the variants of FSGS and age of patients $(\mathrm{P}=0.02)$. In fact, age difference between the tip variant with the rest of variants was significant while this variant was observed at younger ages compared to other variants.

The mean of serum creatinine was $1.41 \pm 0.84 \mathrm{mg} / \mathrm{dl}$, with creatinine ranges from 0.5 to $7 \mathrm{mg} / \mathrm{dL}$. The mean of serum creatinine in each of the variants was as follows: 
Table 1. Patients' data

\begin{tabular}{lccccccc}
\hline Variants & $\begin{array}{c}\text { Total } \\
\text { percent }\end{array}$ & $\begin{array}{c}\text { Male } \\
(\%)\end{array}$ & $\begin{array}{c}\text { Female } \\
(\%)\end{array}$ & $\begin{array}{c}\text { Mean of the } \\
\text { age }(\mathbf{y})\end{array}$ & $\begin{array}{c}\text { Mean of serum } \\
\text { creatinine }(\mathbf{m g} / \mathbf{d L})\end{array}$ & $\begin{array}{c}\text { Mean of } \\
\text { proteinuria } \\
\text { (mg/d) }\end{array}$ & $\begin{array}{c}\text { Mean of glomeruli } \\
\text { with total sclerosis } \\
\text { (number) }\end{array}$ \\
\hline interstitial fibrosis \\
$(\%)$
\end{tabular}

NOS; not otherwise specified variant of FSGS.

NOS variant, $1.48 \pm 0.71 \mathrm{mg} / \mathrm{dL}$; Tip variant, $1.29 \pm 0.87$ $\mathrm{mg} / \mathrm{dL}$, and in perihilar variant, serum creatinine was $1.41 \pm 0.96 \mathrm{mg} / \mathrm{dL}$.

The number of patients under 40 years of age was 133 and the number of patients over 40 years was 101 patients. The mean serum creatinine in patients under 40 years was $1.37 \pm 0.94 \mathrm{mg} / \mathrm{dL}$ while in patients over 40 years was 1.57 $\pm 0.78 \mathrm{mg} / \mathrm{dL}$. We found no significant difference between serum creatinine in two groups $(P=0.29)$.

In our study, 24-hour proteinuria was varied from 221 $\mathrm{mg} / \mathrm{d}$ to $6600 \mathrm{mg} / \mathrm{d}$ (mean of 24-hour proteinuria was $2201.8 \pm 1134.49 \mathrm{mg} / \mathrm{d}$ ). The mean 24 -hour proteinuria in each of the variants was as follows:

The proteinuria in NOS variant of FSGS was $2199.28 \pm 1085.79 \mathrm{mg} / \mathrm{d}$, in tip variant the 24 hours proteinuria was $2154.47 \pm 1205.17 \mathrm{mg} / \mathrm{d}$, while in perihilar variant the proteinuria was $2169.30 \pm 1069.70 \mathrm{mg} / \mathrm{d}$.

In this study no significant correlation between the variants of FSGS and proteinuria was detected $(P=0.96)$. Similarly, no significant correlation between the variants of FSGS and serum creatinine was seen $(P=0.36)$.

The mean percentage of globally sclerotic glomeruli was $16.27 \pm 19.61 \%$. The mean percentage of globally sclerotic glomeruli in each variant was as follows: NOS; $20.52 \pm 21.67 \%$. In tip variant, it was $11.71 \pm 14.96 \%$, while in perihilar variant the percentage of globally sclerotic glomeruli was $14.10 \pm 18.86 \%$.

The relationship between the variants of FSGS and the percentage of globally sclerotic glomeruli was significant $(P=0.011)$. In fact, the difference between NOS variant and tip variant was considerable. The percentage of glomeruli with globally sclerotic glomeruli was higher in
NOS variant compared to tip variant.

The mean percentage of interstitial fibrosis was 12.7 $\pm 17.54 \%$. The mean percentage of interstitial fibrosis in each of the variants was as follows: in NOS variant, it was $14.90 \pm 10.87 \%$; In tip variant it was $7.26 \pm 11.55 \%$, while in perihilar variant it was $10.79 \pm 15.75 \%$.

The association between the variants of FSGS and the percentage of interstitial fibrosis was significant $(P=$ $0.01)$. The difference between NOS variant and tip variant was considerable. We found the percentage of interstitial fibrosis in NOS was more than tip variant $(P=0.01)$.

\section{Discussion}

In recent years much attention has been directed toward the variants of FSGS. This study provides some information about the prevalence of variants of FSGS and clinicopathologic and demographic characteristics of each of the variants in Iran. We found, NOS variant was the most common variant of focal and segmental glomerulosclerosis (42.9\%), which was consistent with other studies (20-27). The second most common variant in our region was tip variant $(32.5 \%)$, while the prevalence of this variant in different regions varied from $4.8 \%$ to $37 \%$ (19-29). In a study conducted in India, tip variant was the most common variant after NOS (25), which was similar to our results. The third most common variant in our study was perihilar variant. This variant was the second most common variant of FSGS in a study (26). It was the third most common variant in China (29), while the prevalence of this variant in Pakistan has been the least after cellular (28). Collapsing and cellular variants with a prevalence of $0.9 \%$ and $0.5 \%$ had the lowest prevalence in

Table 2. Published studies in variants of FSGS

\begin{tabular}{lcccccc}
\hline & $\begin{array}{c}\text { Present } \\
\text { (Pakistan) (28) }\end{array}$ & $\begin{array}{c}\text { Nada et al } \\
\text { (Indian) (25) }\end{array}$ & $\begin{array}{c}\text { Deegens et al } \\
\text { (Dutch) (24) }\end{array}$ & $\begin{array}{c}\text { Shi et al } \\
\text { (Chinese) (29) }\end{array}$ & $\begin{array}{c}\text { Thomas et al } \\
\text { (Multiethnic) (26) }\end{array}$ & $\begin{array}{c}\text { Testagrossa et al } \\
\text { (Brazilian) (30) }\end{array}$ \\
\hline FSGS-NOS & 76.6 & 72.5 & 55.9 & 32 & 42 & 38.2 \\
Collapsing & 12 & 2 & 6.9 & 5 & 37 & 11 \\
Tip & 9.8 & 13.5 & 4.8 & 6.9 & 17 & 26 \\
Perihilar & 1.1 & 4 & 25.5 & 0 & 3.9 \\
Cellular & 0.5 & 8 & & 3.9 & 36 \\
\hline
\end{tabular}


our study. These variants also had the lowest rate in China and multiethnic studies (26-30) (Table 2).

In our study, $58 \%$ were male. In other studies, most patients were also male (27). Our study showed an association between variants of FSGS and age $(P=0.02)$. We found, age difference between the tip variant with the rest of variants was significant, while this variant was observed at younger ages compared to other variants. In the case of biochemical parameters, no relationship between variants of FSGS and serum creatinine $(P=0.36)$ was seen. Likewise, in a study conducted in India, no relationship between variants of FSGS and serum creatinine was detected (25). However, in a study in Pakistan (28) and in a study in the Netherlands (24), the relationship between focal and variants of segmental glomerulosclerosis with creatinine was significant. This study also showed no relationship between variants of FSGS with levels of proteinuria $(P=$ $0.96)$, which is in contrast to a study conducted in India (25). In the case of morphological features, the percentage of totally sclerotic glomeruli was different in the variants of FSGS. The least amount of totally sclerotic glomeruli was in tip variant $(11.71 \pm 14.96 \%)$ whilst most of global sclerosis was detected in the NOS variant $(20.52 \pm 21.76 \%)$. In a study conducted in Pakistan the least amount of glomerular damage has been detected in tip variant but its highest amount was in perihilar variant (27). Additionally a relationship between different variants of FSGS with percent interstitial fibrosis was observed $(P=0.01)$. The lowest amount of interstitial fibrosis was seen tip variant $(7.26 \pm 11.55 \%)$ while the highest value was detected in NOS variant $(14.90 \pm 10.87 \%)$.

\section{Conclusion}

The prevalence of variants of FSGS according to Colombia classification is different in various regions. The most common variant of FSGS in our region like most studies is NOS (classic) variant. We found, FSGS is more common in men like other areas.

\section{Limitations of the study}

This study was retrospective and was conducted in a single center. Additionally, the study was a cross-sectional without respect to treatment or follow up to find the final outcome of patients.

\section{Acknowledgments}

This study has been retrieved from the general medical thesis of Fahimeh Fatehi. The study has been approved in water and electrolytes Research Center (\#394547). Hereby we thank and offer our gratitude to authors of the research center of water and electrolytes.

\section{Authors' contribution}

$\mathrm{HN}$ reported the renal biopsies and edited the draft. FF gathered the data and wrote the primary manuscript.
SMH analyzed the data. All authors read, revised, and approved the final manuscript.

\section{Conflicts of interest}

None.

\section{Ethical considerations}

Ethical issues (including plagiarism, data fabrication, double publication) have been completely observed by the authors.

\section{Funding/Support}

None.

\section{References}

1. Korbet SM. Treatment of primary FSGS in adults. J Am Soc Nephrol. 2012; 23:1769-76. doi: 10.1681/ASN.2012040389.

2. Deegens JKJ, Steenbegen EJ, Wetzels JFM. Review on diagnosis and treatment of focal segmental glomerulosclerosis. Neth J Med. 2008; 66:3-12.

3. D' Agati V. The many masks of focal segmental glomerulosclerosis. Kidney Int. 1994; 46:1223-41.

4. Cameron JS. The enigma of focal segmental glomerulosclerosis. Kidney Int. 1996; 50:S119-S131.

5. Korbet SM. Primary focal segmental glomerulosclerosis. J Am Soc Nephrol. 1998; 9:1333.

6. Meyrier A.E pluribus unum: The riddle of focal segmental glomerulosclerosis. Semin Nephrol. 2003; 23:135-40. doi:10.1053/snep.2003.50013.

7. Haas M, Spargo BH, Coventry S. Increasing incidence of focal segmental glomerulosclerosis among adult nephropathies: a 20-years renal biopsy study. Am J Kidney Dis. $1995 ; 26: 740-50$.

8. Haas M, Meehan SM, Karrison TG, Spargo BH. Changing etiologies of unexplained adult nephrotic syndrome: a comparison of renal biopsy findings from 1976-1979 and 1995-1997. Am J Kidney Dis .1997; 30:621-31.

9. Korbet SM, Schwartz MM, Lewis EJ. Primary focal segmental glomerulosclerosis: clinical course and response to therapy. Am J Kidney Dis. 1994; 23:773-83?

10. Ibrahim Seif E, Abdel-Salam Ibrahim E, Galal Elhefnawy N, Ibrahim Salman M. Histological patterns of idiopathic steroid resistant nephrotic syndrome in Egyptian children: A single centre study. J Nephropathol. 2013;2:53-60.

11. Rydel JJ, Korbet SM, Borok RZ, Schwartz MM. Focal segmental glomerular sclerosis in adults: presentation, course, and response to treatment. Am J Kidney Dis. 1995; 25:534-42.

12. Kitiyakara C, Kopp JB, Eggers P. Trends in the epidemiology of focal segmental glomerulosclerosis. Sem Nephrol. 2003; 23:172-82.

13. Kazi JI, Mubarak M, Ahmed E, Akhter F, Naqvi SA, Rizvi SA. Spectrum of glomerulonephritides in adults with nephrotic syndrome in Pakistan. Clin Exp Nephrol. 2009; 13:38-43.

14. Mubarak M, Lanewala A, Kazi JI, Akhter F, Sher A, Fayyaz A, et al. Histopathological spectrum of childhood nephrotic syndrome in Pakistan. Clin Exp Nephrol. 2009; 13:589-93. 
doi: 10.1007/s10157-009-0216-0.

15. Lanewala A, Mubarak M, Kazi JI, Akhter F, Sher A, Fayyaz A, et al. Treatment and prognosis of primary focal segmental glomerulosclerosis in children from Pakistan. Saudi J Kidney Dis Transplant.2012; 23:513-20.

16. Chang JH, Kim DK, Kim HW, Park SY, Yoo T-H, Kim BS, Kang S-W, Choi KH, Han D-S, Jeong HJ, Lee HY. Changing prevalence of glomerular diseases in Korean adults: a review of 20 years of experience. Nephrol Dial Transplant. 2009;24:2406-2410. doi: 10.1093/ndt/gfp091.

17. D'Agati V. Pathologic classification of focal segmental glomerulosclerosis. Sem Nephrol. 2003; 23:117-34.

18. D’Agati V, Fogo AB, Bruijin JA, Jennette JC. Pathologic classification of focal segmental glomerulosclerosis: a working proposal. Am J Kidney Dis. 2004; 43:368-82.

19. Ardalan MR, Nasri H. Re: Kartagener syndrome with focal segmental glomerulosclerosis. Iran J Kidney Dis. 2014;8:348-9.

20. D'Agati VD, Alster JM, Jennette JC, Thomas DB, Pullman J, Savino DA, et al. Association of histologic variants in FSGS clinical trial with presenting features and outcomes. Clin J Am Soc Nephrol. 2013; 8:399-406. doi: 10.2215/ CJN.06100612.

21. Chun MJ, Korbet SM, Schwartz MM, Lewis EJ. Focal segmental glomerulosclerosis in nephrotic adults: presentation, prognosis, and response to therapy of the histologic variants. J Am Soc Nephrol .2004; 15:2169-77. DOI:10.1097/01.ASN.0000135051.62500.97.

22. Korbet SM. Clinical picture and outcome of primary focal segmental glomerulosclerosis. Nephrol Dial Transplant. 1999; 14:68-73.

23. Cameron JS. Focal segmental glomerulosclerosis in adults.
Nephrol Dial Transplant. 2003; 18:vi45-vi51.

24. Deegens JK, Steenbergen EJ, Borm EF, Wetzels JFM. Pathological variants of focal segmental glomerulosclerosis in an adult Dutch population-epidemiology and outcome. Nephrol Dial Transplant .2008; 23:186-92. DOI:10.1093/ ndt/gfm523.

25. Nada R, Kharbanda JK, Bhatti A, Minz RW, Sakhuja V, Joshi K. Primary focal segmental glomerulosclerosis in adults: is the Indian cohort different? Nephrol Dial Transplant.2009; 24:3701-3707. doi: 10.1093/ndt/gfp328.

26. Thomas DB, Franceschini N, Hogan SL, Ten Holder S, Jennette CE, Falk RJ, et al. Clinical and pathologic characteristics of focal segmental glomerulosclerosis pathologic variants. Kidney Int .2006; 69:920-6. DOI:10.1038/sj.ki.5000160.

27. Taneda S, Honda K, Uchida K, Nitta K, Yumura W, Oda H. et al. Histological heterogeneity of glomerular segmental lesions in focal segmental glomerulosclerosis. Int Urol Nephrol. 2012; 44:183-96. doi: 10.1007/s11255-011-9932-y.

28. Shakeel S, Mubarak M, I Kazi J, Jafry N, Ahmed E. Frequency and clinicopathological characteristics of variants of primary focal segmental glomerulosclerosis in adults presenting with nephrotic syndrome. J Nephropathol. 2013; 2:28-35. doi: 10.5812/nephropathol.8959.

29. Shi SF, Wang SX, Zhang YK, Zhao MH, Zou WZ. Clinicopathologic study of different variants of focal segmental glomerulosclerosis. Zhonghua Bing Li Xue Za Zhi. 2007; 36:11-4.

30. Testagrossa LA, Malheiros DM. Study of the morphologic variants of focal segmental glomerulosclerosis: a Brazilian report. J Bras Pathol Med Lab. 2012; 48:211-5.

Copyright $\odot 2019$ The Author(s); Published by Published by Society of Diabetic Nephropathy Prevention. This is an open-access article distributed under the terms of the Creative Commons Attribution License (http://creativecommons.org/licenses/by/4.0), which permits unrestricted use, distribution, and reproduction in any medium, provided the original work is properly cited. 